\title{
El papel del vínculo psicoafectivo familiar en el tránsito de la educación presencial a la educación virtual y remota en el marco de la emergencia sanitaria por la Covid-19
}

\author{
The Role of the Family Psycho-Affective Bond in the Transit from \\ Face-to-Face Education to Virtual and Remote Education in the \\ Health Emergency Framework for the Covid-19
}

Luisa F. Amaya-Lópeza (i)

Recibido: 02-04-2020; Aceptado: 12-06-2020

\section{RESUMEN}

El Vínculo Psicoafectivo Familiar se considera un concepto fundamental en el desarrollo social y afectivo del ser humano, el cual ha sido estudiado por las ciencias humanas con gran minuciosidad y detalle. De igual manera, existe una gran revisión documental de este tema y su relación con los procesos de enseñanza-aprendizaje. Sin embargo, en la praxis de la educación, los Vínculos Psicoafectivos Familiares pasan a un segundo plano y son los procesos cognitivos los que cobran relevancia desarticulando esta dupla psicológica de la cual depende el éxito de la formación a lo largo de la vida. Por lo anterior, es de resaltar que el tránsito de la Educación Presencial a la Educación Virtual y Remota, en el marco de la Emergencia Sanitaria por Covid-19 que vive el mundo entero, ha sido un gran reto para Docentes, Padres, Estudiantes y Sistema Educativo. Sin embargo, esta coyuntura ha obligado a que la Escuela se traslade a la sencillez del hogar, y, con ello, se retoma la esencia de los Vínculos Psicoafectivos Familiares en los procesos pedagógicos y la implicación de la Familia en la formación integral del ser humano. Por lo anterior, este artículo reflexivo tiene como objetivo analizar la importancia del Vínculo Psicoafectivo Familiar en el tránsito de la Educación Presencial a la Educación Virtual y Remota, en el marco de la Emergencia Sanitaria por el Virus Covid-19, y el autor apoya su criterio en la necesidad de articular -en los Niños y Adolescentes- los procesos afectivos con los cognitivos en esta nueva forma de educación desde casa, concluyendo que, este nuevo enfoque de enseñanza, basado en la sincronicidad de estos dos componentes, abren la posibilidad de una revolución educativa. A lo largo de este artículo, se abordarán dos posturas fundamentales: en primer lugar, se presenta una explicación teórica sucinta de la disfuncionalidad del Vínculo Psicoafectivo Familiar y Escolar en la Educación Tradicional. Y, por otra parte, la necesidad de la reconstrucción del vínculo afectivo en el tránsito de la Educación Presencial a la Educación Virtual y Remota, en el marco de la Emergencia Sanitaria por el Virus Covid-19.

Palabras clave: Vínculo psicoafectivo; Procesos cognitivos; Educación Virtual; Revolución Educativa; Educación Presencial; Familia; Educación; Covid-19; Pandemia.

aInstitución Educativa Cristóbal Colón, Coordinación académica, Morroa, Colombia. Universidad Nacional Abierta y Distancia, Escuela de Ciencias Sociales, Artes y Humanidades, Corozal, Colombia. criscolcoordinacionpbp@gmail.com

Como citar (APA)

Amaya-López, L. F. (2020). El papel del vínculo psicoafectivo familiar en el tránsito de la educación presencial a la educación virtual y remota en el marco de la emergencia sanitaria por la Covid-19. Búsqueda, v. 7, n. 24, e492. https://doi.org/10.21892/01239813.492 


\begin{abstract}
The Family Psycho-Affective Bond is considered a fundamental concept in the social and affective development of the human being, which has been studied by the human sciences with great thoroughness and detail. Similarly, there is a great documentary review of this topic and its relationship with the teaching-learning processes. However, in the praxis of education, the Family Psycho-Affective Bonds take second place and it is the cognitive processes that take on relevance, disarticulating this psychological pair on which the success of training throughout life depends. Therefore, it is noteworthy that the transition from Face-to-Face Education to Virtual and Remote Education, in the context of the Covid-19 Health Emergency that the entire world is experiencing, has been a great challenge for Teachers, Parents, Students and Educational System. However, this situation has forced the school to move to the simplicity of the home, and with it, the essence of Family Psycho-Affective Bonds in pedagogical processes and the involvement of the family in the integral formation of the human being, is retaken. Therefore, this reflective article aims to analyze the importance of the Family Psycho-Affective Bond in the transition from Faceto-Face Education to Virtual and Remote Education, in the framework of the Health Emergency due to the Covid-19 Virus, and the author supports his criteria in the need to articulate -in the Children and Adolescents - the affective processes with the cognitive ones in this new form of education from home, concluding that, this new teaching approach, based on the synchronicity of these two components, opens up the possibility of an educational revolution. Throughout this article, two fundamental positions will be addressed: first, a succinct theoretical explanation of the dysfunctionality of the Family and School Psycho-Affective Bond in Traditional Education is presented. And, on the other hand, the need to reconstruct the Affective Bond in the transition from Face-to-Face Education to Virtual and Remote Education, within the framework of the Health Emergency due to the Covid-19 Virus.
\end{abstract}

Keywords: Psycho-affective bond; Cognitive processes; Virtual education; Educational revolution; Face-to-face education; Family; Education; Covid-19; Pandemic

\title{
INTRODUCCIÓN
}

A lo largo de la construcción teórica y metodológica de las teorías evolutivas humanas se ha enmarcado como eje principal de estas la construcción de Vínculos Afectivos Familiares, como andamiaje fundamental para el desarrollo cognitivo de los Niños y Adolescentes de todos los contextos o culturas mundiales.

Desde los primeros esbozos psicológicos de la Teoría del Apego, sustentada por John Bowlby, (2006) deja por sentado que: "existe una necesidad humana universal para formular vínculos afectivos estrechos" (p. 249). Lo que es imposible de desconocer en el proceso de enseñanzaaprendizaje. En este sentido, según el autor, el ser humano en sus primeros años de vida no cuenta con la capacidad de autorregularse y esto solo lo logra con la ayuda de sus figuras significativas, quienes atienden y satisfacen sus necesidades básicas. Por lo anterior, son este cúmulo de experiencias vividas con su objeto de amor primario las que el infante incorpora en sus modelos representacionales y repite sistemáticamente en diversos escenarios y con diferentes autores a lo largo de la vida, incluyendo su Escuela y sus Maestros.

Es de esta forma que la teoría psicoafectiva empieza a entrelazarse de manera sustancial y estrecha con las teorías cognoscitivas, conglomerando un sinnúmero de investigaciones que correlacionan los lazos afectivos familiares con el desarrollo y construcción del aprendizaje infantil. Las evidencias teóricas demuestran que un niño o un adolescente, con un escenario familiar psicoafectivo saludable contará con factores protectores en su esquema mental que les permitirá: un adecuado desarrollo intelectual, superioridad en el lenguaje oral y escrito, procesos metacognitivos avanzados, mayor destreza lectora, entre otras potencialidades que le aseguran éxito en la vida (Lafuente, 2000).

Es claro que el primer escenario de vida de los Niños es la Familia, el cual se convierte en un referente social que determina en gran medida la manera como el infante se relacionará e 
interactuará a lo largo de su ciclo vital (Cava, Musitu, y Murgui, 2006). Sin embargo, al este pasar a la escolarización la Escuela se constituye en el espacio donde el Niño transfiere a sus Maestros los vínculos afectivos provenientes de sus sistemas familiares, y el Maestro, a su vez, se transforma en una figura paternal que favorecerá o entorpecerá el desarrollo cognitivo de sus Estudiantes. Es así como la Escuela y la Familia son los epicentros del proceso de enseñanza- aprendizaje, donde debe existir una sincronía de acciones y reacciones que propendan al crecimiento integral del ser humano.

Muy distante del precepto citado en el párrafo anterior, está la realidad educativa que vivencia Colombia, en la cual la sincronicidad entre la Escuela y la Familia se encuentra desarticulada. En primer lugar, al Maestro se le dificulta comprender la importancia del afecto en la educación y no logra reconocer que la sociedad en que vivimos es compleja, incoherente y desigual (Instituto para la Investigación Educativa y el Desarrollo Pedagógico [IDEP], 2018). Por otro lado, y más traumático aún, se evidencia que los sistemas familiares no cumplen con el rol psicoafectivo necesario para lograr un aprendizaje significativo en sus hijos, depositando en los Maestros y Escuelas la mayor responsabilidad en el proceso de enseñanza, olvidando como lo menciona Ramos (2002):

La Familia y Escuela son un marco referencial imprescindible para la incorporación de un nuevo ser humano a la sociedad; pero, este marco se encuentra a merced de los avatares impuestos por transformaciones diversas que han de asumir ambas instituciones si quieren responder a su tarea educativa y socializadora (p. 205).

Sin embargo, la Emergencia Sanitaria que se presenta en la actualidad por el Virus Covid-19 y la medida de confinamiento social dispuesto el Gobierno nacional, ha obligado a los sistemas familiares y, en especial, a los Estudiantes, aislarse de manera preventiva en sus hogares, abandonando de manera abrupta la Presencialidad de la clases y se ha extrapolado a la Familia la responsabilidad de formar y educar a sus hijos, no solo en el componente ético, moral, social, como siempre se le ha aludido, sino también en las áreas del conocimiento como son: Matemáticas, Castellano, Ciencias Sociales y Naturales, entre otras (Suárez Ortiz y Urrego Murillo, 2014). Esta medida, sin duda, obliga a los padres a volcar su atención en los Niños y Adolescentes, a la vez que cuestiona la importancia de las relaciones psicoafectivas iniciales, las cuales son necesarias para la construcción de vínculos seguros en los seres humanos y facilitar, con ello, el proceso de enseñanza-aprendizaje a lo largo de la vida.

A partir del panorama descrito anteriormente, el autor del presente artículo realizar los siguientes cuestionamientos: ¿Cómo el rol que los padres asumen en la vida de los Niños y Adolescentes pueden agitar su ambiente para permitirles a estos un aprendizaje significativo? y ¿cómo los vínculos psicoafectivos cobran relevancia en los procesos educativos de - los Niños y Adolescentes - en la medida que el Padre de Familia y el Maestro cumplen de manera conjunta con la construcción del conocimiento?, son estos interrogantes se apuntan a resolver en los apartados que se describirán a continuación.

\section{DESARROLLO}

Disfuncionalidad del Vínculo Psicoafectivo Familiar y Escolar en la Educación Tradicional. Según la Teoría del Apego, el desarrollo de la personalidad está determinado por la presencia o ausencia de una figura de amor que proteja y supla las necesidades, y le asegure al infante que el mundo es un lugar digno de confiar. Es así, como los padres constituyen la base segura para sus hijos, los cuales inician a explorar el mundo por medio de ellos. La teoría propuesta por diversos estudiosos del ciclo vital indica que la manera como el Niño se vincula en los primeros momentos de vida continuará repitiéndose sistemáticamente con todas las figuras que representen a estos objetos primarios (Bowlby, 2006).

En investigaciones como las que realizaron Mary y Main (1985), se describieron varios tipos de apego en edades posteriores, de acuerdo con las primeras vivencias infantiles que experimentaban los Niños: 
- Apego Seguro: Quienes constituyeron este vínculo con sus padres o cuidadores se caracterizan por ser personas con relaciones afectivas estables y con gran capacidad para reflexionar sobre sus acciones.

- Apego Inseguro Despreocupado: Quienes constituyen este tipo de vínculo presentan poco interés en relacionarse con los demás, y ante una separación o pérdida significativa no muestra preocupación alguna.

- Apego Inseguro Preocupado: Los individuos con este tipo de apego manejan relaciones conflictivas y confusas; suelen reaccionar de manera violenta y agresiva ante una ruptura o separación (Vernengo, 2009, p. 1).

En este sentido, la forma como se genera el vínculo afectivo entre el Niño y la Familia se reflejará en los procesos educativos que se imparten en las Escuelas. Sin embargo, existe en las Instituciones Educativas colombianas una interrupción entre el canal de comunicación y la vinculación EscuelaFamilia; autores como Cárdenas y Restrepo (1991), citados por Pérez y Arrazola (2013, p. 21), afirman que "el proceso comunicativo es el que enlaza las relaciones Familiares y es revelador de los contenidos en las interacciones filial-fraternal-parental, es la expresión de cada relación con el otro", dejando esto en evidencia la disfuncionalidad del vínculo Familia-Escuela, el cual repercute de manera directa en los avances académicos de los Niños y Adolescentes.

Todo lo anterior explica cómo la Familia, a lo largo de la historia, está llamada a realizar un acompañamiento intimo a la Escuela. Es por esto que Flórez, Villalobos y Londoño (2017) describen la Familia como un escenario cuya competencia exclusiva es:

Sustentar el vínculo, consolidar la unión de sus miembros, establecer propósitos, diseñar soluciones y alcanzar sueños que permiten a cada uno de sus integrantes vivir a plenitud la experiencia de una vida gratificante y exitosa de acuerdo al interés que postula de manera conjunta o individual como condición de institucionalidad (p. 5).

A partir de los argumentos anteriores, es válido para el autor afirmar, que la Educación Presencial impartida a lo largo de la historia educativa colombiana, está psicológicamente construida en una disfuncionalidad del Vínculo Psicoafectivo Familiar y Escolar, lo que no solo ha alterado la salud mental de muchas generaciones, sino que impacta de manera desbordada en el desarrollo adecuado de los procesos cognitivos superiores de los Estudiantes. Para explicar con exactitud este postulado, es importante comprender que es una disfuncionalidad, según la Real Academia Española (RAE) "una disfuncionalidad obedece al desarreglo en el funcionamiento de algo" (Sección Diccionario, párr. 2), que en este caso ese desajuste se referiría al vínculo afectivo, el cual debe ser sano y seguro entre el infante con sus padres al inicio del ciclo vital, para que, una vez instituido, se mantenga esa estructura en la relación Familia-Escuela.

Es decir, la construcción vincular inicial del apego infantil con sus figuras parentales se verá proyectada en años posteriores en los escenarios escolares, según se gestó en los primeros años de vida, porque como lo explica, Flórez et al., (2017): "El vínculo afectivo cohesiona las dinámicas interpersonales y sociales, que motivan al Estudiante a cumplir de forma voluntaria y consciente con unas expectativas, entendidas como consecuentes según la intensión de la Familia" (p. 9). Por lo tanto, un Niño cuyo vínculo inicial con su Familia se conformó de manera insegura, se verá develado en el entorno educativo con las siguientes manifestaciones: falta de acompañamiento familiar en las actividades escolares, ansiedad e inseguridad por parte del Estudiante en la resolución de pruebas y exámenes, desesperanza aprendida ante la imposibilidad de mejorar el rendimiento académico, poca o nula comunicación del Maestro con el Sistema Familiar, ausentismo escolar injustificado, pérdida del interés por el estudio, desafección del aprendizaje, percepción de la figura del Maestro como amenazadora, entre otros síntomas nefastos.

En este punto se debate el primer cuestionamiento propuesto por el autor en el artículo ¿Cómo el rol que los padres asumen en la vida de los Niños y Adolescentes pueden agitar su ambiente para permitirles a estos un aprendizaje significativo? , por lo cual es válido considerar que, vincular psicoafectivamente a la Familia con el proceso educacional del Niño no es tarea fácil; incluso, desde los lineamientos curriculares otorgados por el Ministerio de Educación Nacional a las Instituciones Educativas son muy limitadas las líneas de acción que propendan al fortalecimiento de vínculos afectivos de la Familia-Escuela (Ministerio de Educación Nacional, 2017). Sin embargo, 
las investigaciones hechas en el tema, siguen mostrando las bondades que tienen los programas enfocados en la educación emocional. Como cita Manrique, Zinke, Russo (2018) a Ambrona, López-Pérez, y Márquez-González, 2012; Morgan, Izard, y Hyde, 2014:

Los hallazgos de otras investigaciones han puesto de manifiesto que educar en el componente emocional determina positivamente el bienestar del infante, porque aumenta el reconocimiento y la regulación de emociones, disminuye los síntomas emocionales y permiten la construcción de un concepto del yo saludable, además de promover la autogestión afectiva" (Sección Conclusiones, párr. 3).

Es, precisamente, a estas soluciones, a las que el Sistema Educativo colombiano debe apuntar para cerrar la brecha de disfuncionalidad vincular existente entre la Familia y la Escuela, principalmente en esta etapa de transición de la Educación Presencial a la Virtual y Remota. El entrenamiento psicoafectivo y emocional Permitirá, la agitación de un ambiente escolar en casa agradable, afectivo y sano, que favorecerá con ello, el desarrollo emocional y, simultáneamente, el aprendizaje significativo de los Estudiantes (Manrique, Zinke y Russo, 2014).

La Reconstrucción del Vínculo Afectivo en el Tránsito de la Educación Presencial a la Educación Virtual y Remota en el Marco de la Emergencia Sanitaria por el Virus Covid19. Cuando se realiza una reflexión epistemológica del ejercicio de la Docencia, es normal evidenciar que al Maestro y el Estudiante, como los principales protagonistas del proceso de enseñanza-aprendizaje, el rol y accionar de la Familia queda en segundo plano; incluso aquellas prácticas de antaño donde la Familia impartía enseñanzas relacionada con el comportamiento social del Estudiante, fueron lentamente sustituidas por el aula de clase, donde quedó supeditado en su totalidad la construcción del saber y del ser, dándole más fuerza al Maestro y a la Institución (Bourdieu, 2014).

Este enfoque reduccionista de los procesos educativos en Colombia ha llevado a repetir cíclicamente este fenómeno, enfocando el entorno escolar como el único espacio de formación integral y desarticulando los vínculos afectivos que se gestan en el seno de la Familia de todo este andamiaje. Sin lugar a dudas, es la Familia el primer ente llamado a cumplir con los dos papeles: por un lado ser eje del conocimiento y, por el otro, asegurar la construcción del vínculo psicoafectivo seguro en los Niños y niñas del país. "La Familia es transmisora de aprendizajes que son producto de las tradiciones más representativas de la misma, lo cual el Niño y el adolescente interioriza en su ser, logrando tomar consciencia de su identidad personal, Familiar y social" (Aguilar, 2002, p. 205).

En el presente año el Sistema Educativo ha vivenciado con la Emergencia Sanitaria causada por el Virus Covid-19 una interrupción abrupta de los Procesos Académicos Presenciales y ha iniciado, bajo el riesgo de la incertidumbre, el tránsito a la Educación Virtual y Remota. Aunque para muchos el reto de este nuevo sistema ha sido la adaptación y la accesibilidad de la comunidad educativa a la aplicación de las Tecnologías de la Información y la Comunicación en las actividades propias del quehacer docente (Abadía, 2020), es sustancial considerar que este revolcón biopsicosocialescolar trae consigo un cambio de perspectiva a fenómenos tan innatos al ser humano como es el vínculo psicoafectivo. Siendo así, los estragos del confinamiento, la sensación humana de vulnerabilidad, la obligatoria convivencia dentro del contexto familiar, ha llevado a los hogares a reconstruir la estructura natural de la educación e iniciar desde la cotidianidad del hogar la invaluable labor de educar a los hijos lejos del aula de clase y del trascendental apoyo del Maestro que, en ocasiones, sustituían las figuras paterno-filiales.

Pareciera, sin lugar a dudas, que esta interrupción momentánea de Labores Presenciales en un aula física fuera un reclamo, un ajuste de cuentas que insta a la humanidad a volver a la estructura más básica del sistema, que es la Familia y, con ella, reconstruir o reorientar la conformación de vínculos psicoafectivos sanos en Niños y Adolescentes de la sociedad. Respondiéndose de esta manera el segundo cuestionamiento postulado por el autor, ¿cómo los vínculos psicoafectivos cobran relevancia en los procesos educativos de - los Niños y Adolescentes - en la medida que el Padre de Familia y el Maestro cumplen de manera conjunta con la construcción del conocimiento? 
Asumir el rol de Educador exige al padre mirar a su hijo a los ojos, tocarlo, hablarle, estar atento a sus necesidades, lo cual, indudablemente, motiva al Niño a ser reconocido como un ser digno de afecto y es precisamente este reconocimiento lo que lo llevará a construir su autonomía cognoscitiva, que favorecerá su desenvolvimiento escolar. García (2010) apoya lo anterior cuando explica la relevancia de la función educadora de la Familia, la cual consiste en cumplir con un sinnúmero de acciones pedagógicas que, por supuesto, son competencia de esta y no de las Escuelas, como se ha pretendido mostrar a la sociedad; como lo son, el acompañamiento físico, mental y moral de los hijos, la comunicación asertiva y el diálogo frecuente con los Docentes.

No se puede desconocer que este tránsito a la Virtualidad tiene una segunda cara, poco alentadora para muchos sistemas familiares, que no cuentan con los factores protectores, ni las herramientas educativas y sociales suficientes para reconstruir con sus hijos los vínculos psicoafectivos necesarios para aprender en la vida; en este sentido, la fe hacia un cambio educativo seguirá enfocado a los referentes de la zona de desarrollo próximo (Vigotsky (2000) citado por Suarez (2004, p.7) como lo son: amigos, Maestros u otros familiares que estabilicen la psique del Niño, la niña y el adolescente cuando la primera impronta familiar falle.

Por esto, se puede reflexionar que, el tránsito de la Presencialidad a la Virtualidad Educativa ha traído muchos cambios, los cuales, en algún momento histórico, se podrán poner en una balanza. Es de esperar para aquellos que le apuestan al potencial humano, que este momento traumático dejará como legado la reconstrucción familiar del tejido psicoafectivo en las nuevas generaciones y, con ello, la esperanza de instaurar un nuevo Sistema Educativo basado en la sincronicidad de la Familia y la Escuela.

\section{CONCLUSIONES}

El Sistema Educativo del mundo, y en este caso de Colombia, a lo largo de su cimentación histórica jamás había enfrentado una situación similar a la actual, la cual ha sido desencadenada por la Emergencia Sanitaria causada por el Virus Covid-19, la cual ha obligado a los Docentes y 9,8 millones de Estudiantes a estar por fuera del aula de manera Presencial desde el pasado 16 de marzo. Zubiria, (2020) considera que:

La Educación Virtual es una decisión compleja, porque los Estudiantes tienen poco acceso a Internet y los profesores en su mayoría no dominan plataformas digitales y es por ello que tendremos que recurrir a otras herramientas como lo son la radio y la televisión pública (Sección Lecciones pedagógicas del Coronavirus, párr. 11).

Esta desestabilización del Sistema Educativo y la obligatoriedad de continuar el proceso de formación bajo la Metodología de Educación Virtual y Remota, ha conllevado que la educación de los Niños y niñas se brinde bajo el acompañamiento permanente de los sistemas familiares, acción que anteriormente era difícil de lograr por la poca receptividad de los padres a las actividades educativas. Flórez et al., (2017) aseguran que:

En un Sistema Educativo como el colombiano, la falta de compromisos por parte de los padres y Familia es bastante marcado, en general, no se ajustan a las condiciones escolares, o no logran vincularse a la Escuela y mucho menos a la constante supervisión estructurada que requieren los Estudiantes para lograr el éxito académico (p. 15).

Ante este panorama, el proceso educativo del país queda amarrado a la esperanza del apoyo que brindan los sistemas familiares a los Estudiantes, y su éxito dependerá directamente de la manera como se ha generado el vínculo afectivo inicial dentro de la Familia y cómo esta corresponde a las necesidades de aprendizaje del Niño. Es por ello, que, en el contexto del confinamiento, sobre los padres recae la obligación de acompañar sus procesos emocionales y de orientarlos en las nuevas tareas que exige la convivencia permanente (Zubiria, 2020).

Es importante anotar que la educación requiere un cambio en diversos aspectos, porque la realidad escolar demuestra que no existen garantías, pertenencia, equidad, calidad en sus 
procesos (Zubiria, 2020). Sin embargo, es clave para el autor de este artículo analizar sobre los cambios que se requieren en el marco del modelo educativo colombiano, los cuales no solo deben apuntar a el proceso de enseñanza-aprendizaje, sino también a una revolución psicoafectiva que permita los Estudiantes y sus Familias la reconstrucción de la esencia vincular-afectiva del hogar, y con ello disminuir el divorcio psíquico y afectivo que tiene la Escuela con la Familia. Autores como Bolivar (2006), respalda lo anterior cuando explica que: "Ni la Escuela es el único contexto de educación ni sus profesores y profesoras los únicos agentes, al menos también la Familia y los medios de comunicación desempeñan un importante papel educativo" (p. 120). Por tanto, si el Sistema Educativo Colombiano no acepta la importancia de estos agentes en el proceso de formación de los Estudiantes, continuarán condenados a repetir el tradicional ciclo proyectivo del vínculo filiar inseguro en la Escuela, el cual se caracteriza por la falta de acompañamiento familiar en el proceso de crecimiento de sus hijos, incluyendo los escenarios educativos y, con ello, las consecuencias catastróficas que este fenómeno trae al proceso de formación del ser humano.

Finalmente, este panorama descrito abre una brecha educativa irreparable, la cual el autor ha decidido denominada como desigualdad psicoafectiva familiar en el contexto escolar concepto nuevo que hace referencia a esa desproporción presente entre los Estudiantes de las diferentes Escuelas del país, donde se evidencia por un lado Niños y Adolescentes provenientes de familias con vínculos psicoafectivos sanos, caracterizados por una alta protección de su integridad física, social y escolar por parte de sus padres; y por otro lado Niños y Adolescentes con sistemas familiares afectados por la disfunción psicoafectiva familiar, que como consecuencia trae un panorama desalentador que se proyecta día a día en el aula, como lo son Estudiantes sin ningún apoyo afectivo, sin protección de su bienestar físico y mental, sin acompañamiento escolar por parte de sus padres lo que marcará para siempre los hitos educativos de su vida. Así como también lo respalda Fonagy Peter (1999).

Es por ello, que en este momento histórico, en materia de salud pública para el País, la lucha no será solamente contra el Virus Covid-19, sino también contra ese cúmulo de experiencias negativas que ha dejado el desapego psicoafectivo de las Familias Colombianas en los procesos educativos de sus hijos y cómo a partir de la reconstrucción de este tejido se debe gestar la nueva revolución educativa, enmarcada en un íntimo equilibrio entre la Familia y la Escuela, las cuales son las redes de apoyo fundamentales para la formación integral de los Niños y Adolescentes de la sociedad.

\section{Conflicto de intereses}

La autora declara no tener ningún conflicto de intereses.

\section{REFERENCIAS}

Abadia, K. (2020). El Reto Que El Sector Educativo En Colombia Debe Superar Tras La Pandemia. Revista Universidad Javeriana. https://www.javeriana.edu.co/documents/12789/11569759/ P\%C3\%A1g. +9. +El+reto+del+sector+educativo. +HJ+marzo+2020+web.pdf/bf0db075be31-413f-8496-e6d72ec72bf9

Bolívar, A. (2006). Familia y Escuela: dos mundos llamados a trabajar en común. Revista de Educación, 339, pp. 119-146. http://www.revistaeducacion.mec.es/re339.htm

Bowlby, J. (2006). Vínculos afectivos: formación, desarrollo y pérdida. Ediciones Morata, S. A.

Cava, M. J.; Musitu, G.; Murgui, S. (2006). Familia y violencia escolar: el rol mediador de la autoestima y la actitud hacia la autoridad institucional. Psicothema, 18 (3): 367-373. https:// www. redalyc.org/articulo.oa? id $=727 / 72718306$ 
Flórez, G., Villalobos, J., Londoño-Vásquez, D. (2017). El acompañamiento Familiar en el proceso de formación escolar para la realidad colombiana: de la responsabilidad a la necesidad. Revista Psicoespacios, Vol. 11, N. 18. http://revistas.iue.edu.co/index.php/Psicoespacios

Fonagy, P. (1999). Persistencias transgeneracionales del apego: una nueva teoría. Aperturas Psicoanalíticas, no 3. https://aperturas.org/articulo.php?articulo $=0000086$

Garcia, B. (2009). Las Dimensiones Afectivas de la Docencia. Revista Digital Universitaria, 10(11). http://www.revista.unam.mx/vol.10/num11/art71/art71.pdf

García, J. (2010). La relevancia de la función Educadora de la Familia. Revista digital innovación y experiencias educativas, 45, pp. 2-7. http://publicacionesdidacticas.com/hemeroteca/ articulo/068028/articulo-pdf

Hervas, E. (2008). Relación Familia Escuela. Revista digital: innovación y experiencias educativas, 13, p. 7. http://www.csi-csif.es/andalucia/mod ense-csifrevistad.html.

Lafuente, J. (2000). Patrones de Apego, pautas de interacción familiar y funcionamiento cognitivo. Revista de psicología general y aplicada, 53(1), 165-190. https://dialnet.unirioja.es/servlet/ articulo?codigo $=2356868$

Manrique-Palacio, K. P., Zinke, L., \& Russo, A. R. (2018). Pisotón: un programa de desarrollo psicoafectivo, como alternativa para construir la paz. Revista Latinoamericana de Ciencias Sociales, Niñez y Juventud, 16(1). https://www.redalyc.org/jatsRepo/773/77355376008/ html/index.html

Ministerio de Educación Nacional (2007). Guía n 26. Cartilla para padres de Familia. ¿Cómo participar en los procesos educativos de la Escuela? https://www.mineducacion.gov.co/1759/ articles-120646 archivo pdf.pdf

Ospina, H., Cano, A. (2016). Educación popular y género: mirada desde América Latina y el Caribe. En: Ospina, H., Ramírez-López, C. (ed.). Pedagogía crítica latinoamericana y género. Siglo del Hombre Editores.

Pérez Contreras, B. y Arrázola, E. T. (2013).Vínculo afectivo en la relación parento-filial como factor de calidad de vida. Tendencias y Retos, 18(1), 17-32. https://dialnet.unirioja.es/ servlet/articulo?codigo $=4929410$

Pérez, D., Londoño, D. (2015). La influencia de la Familia en el desempeño académico de los y las adolescentes del grado sexto en tres instituciones de Antioquia. Revista Psicoespacios 9(15), pp. 215-233. http://revistas.iue.edu.co/index.php/Psicoespacios/issue/view/36/showToc

Quintero, M., Sánchez K. y Mateus J. (2015). Pedagogía de las Emociones Para la Paz. https:// repositorio.idep.edu.co/handle/001/251

Real Académica Española (2014). Diccionario de la Real Academia Española. RAE. https://dle. rae.es/

Romero, G., Martínez, J. y Londoño, D. (2017) El Acompañamiento Familiar En El Proceso De Formación Escolar Para La Realidad Colombiana: De La Responsabilidad A La Necesidad. Revista Virtual de Ciencias Sociales y Humanas, 11(18). https://doi.org/10.25057/21452776.888

Suárez Guerrero, C. (2004). La zona de desarrollo próximo, categoría pedagógica para el análisis de la interacción en contextos de virtualidad. Pixel-Bit. Revista de Medios y Educación, (24): 5-10. https://www.redalyc.org/articulo.oa?id=368/36802401. 
Amaya-López - El papel del vínculo psicoafectivo familiar en la educación virtual en el marco de la Covid-19

Suárez, J., Urrego, L. (2014). Relación Familia-Escuela: Una mirada desde las prácticas pedagógicas rurales en Anserma, Caldas. Revista Latinoamericana de estudios de Familia, 6, pp. 97-113. http://vip.ucaldas.edu.co/revlatinoFamilia/downloads/Rlef6 6.pdf

Vernengo, P. (2009). Apego. Psicoanálisis Ayer y hoy. https://www.elpsicoanalisis.org.ar/old/ numero4/resenaapego4.htm

Zubiria, J. (04/06/2020). La Educación en Tiempos de Cuarentena. Revista Semana. https:// www.semana.com/opinion/articulo/la-educacion-en-tiempos-de-cuarentena-columna-dejulian-de-zubiria/661969

Zubiria, J. (15/03/2020). Lecciones Pedagógicas del Coronavirus. Revista Semana. https://www. semana.com/opinion/articulo/lecciones-pedagogicas-del-coronavirus-columna-de-juliande-zubiria/656986 